\title{
Correction to: Identification of a Rule to Predict Response to Sarilumab in Patients with Rheumatoid Arthritis Using Machine Learning and Clinical Trial Data
}

Markus Rehberg • Clemens Giegerich • Amy Praestgaard • Hubert van Hoogstraten • Melitza Iglesias-Rodriguez • Jeffrey R. Curtis · Jacques-Eric Gottenberg • Andreas Schwarting · Santos Castañeda • Andrea Rubbert-Roth • Ernest H. S. Choy (D) on behalf of the MOBILITY, MONARCH, TARGET, and ASCERTAIN investigators

Published online: October 29, 2021

(C) The Author(s) 2021

Correction to: Rheumatol Ther https://doi.org/10.1007/s40744-021-00361-5

In the original article published, there is an error in the video of the supplementary

The original article can be found online at https://doi. org/10.1007/s40744-021-00361-5.

Supplementary Information The online version contains supplementary material available at https:// doi.org/10.1007/s40744-021-00389-7.

M. Rehberg · C. Giegerich

Sanofi, Frankfurt, Germany

e-mail: markus.rehberg@sanofi.com

C. Giegerich

e-mail: clemens.giegerich@sanofi.com

A. Praestgaard · H. van Hoogstraten .

M. Iglesias-Rodriguez

Sanofi, Cambridge, MA, USA

e-mail: amy.praestgaard@sanofi.com

H. van Hoogstraten

e-mail: hubert.vanhoogstraten@sanofi.com

M. Iglesias-Rodriguez

e-mail: melitza.iglesias-rodriguez@sanofi.com

J. R. Curtis

Division of Clinical Immunology and

Rheumatology, University of Alabama at

Birmingham, Birmingham, AL, USA

e-mail: jrcurtis@uabmc.edu

\section{J.-E. Gottenberg}

Strasbourg University Hospital, Strasbourg, France e-mail: jegotten@gmail.com material. The correct supplementary material has been updated.

The original article has been corrected.

\section{OPEN ACCESS}

This article is licensed under a Creative Commons Attribution-NonCommercial 4.0 International License, which permits any non-

\section{A. Schwarting}

Acura Kliniken Rheinland-Pfalz AG, Bad Kreuznach, Germany

\section{A. Schwarting}

University Center of Autoimmunity, University

Medical Center Mainz, Mainz, Germany

e-mail: schwarting@uni-mainz.de

\section{S. Castañeda}

Rheumatology Division, Hospital Universitario de La Princesa, IIS-IP and EPID-Future Cátedra, Autónoma University of Madrid (UAM), Madrid, Spain

e-mail: scastas@gmail.com

\section{A. Rubbert-Roth}

Kantonsspital St Gallen, St Gallen, Switzerland e-mail: andrea.rubbert-roth@kssg.ch

E. H. S. Choy ( $₫)$

Section of Rheumatology and Translational Research, Division of Infection and Immunity, Arthritis Research UK CREATE Centre and Welsh Arthritis Research Network (WARN), Cardiff University School of Medicine, Tenovus Building, Heath Park Campus, Cardiff CF14 4XN, UK e-mail: choyeh@cardiff.ac.uk 
commercial use, sharing, adaptation, distribution and reproduction in any medium or format, as long as you give appropriate credit to the original author(s) and the source, provide a link to the Creative Commons licence, and indicate if changes were made. The images or other third party material in this article are included in the article's Creative Commons licence, unless indicated otherwise in a credit line to the material. If material is not included in the article's Creative Commons licence and your intended use is not permitted by statutory regulation or exceeds the permitted use, you will need to obtain permission directly from the copyright holder. To view a copy of this licence, visit http://creativecommons.org/licenses/by$\mathrm{nc} / 4.0 /$. 